\title{
Hybrid therapy for hypoplastic left heart syndrome: Myth, alternative, or standard?
}

\author{
Can Yerebakan, MD, Klaus Valeske, MD, Hatem Elmontaser, MD, Uygar Yörüker, MD, \\ Matthias Mueller, MD, Josef Thul, MD, Valesco Mann, MD, Heiner Latus, MD, Anika Villanueva, BSc, \\ Karoline Hofmann, MS, Dietmar Schranz, MD, and Hakan Akintuerk, MD
}

\section{ABSTRACT}

Objective: This retrospective study presents our operative results, mortality, and morbidity with regard to pulmonary artery growth and reinterventions on the pulmonary artery and aortic arch, including key features of our institutional standards for the 3-stage hybrid palliation of patients with hypoplastic left heart syndrome.

Methods: Between June 1998 and February 2015, 182 patients with hypoplastic left heart structures underwent the Giessen hybrid stage I procedure. Among these, 126 patients with hypoplastic left heart syndrome who received a univentricular palliation or heart transplantation were included in the main analysis. Median age and body weight of patients at hybrid stage I were 6 days (0-237) and $3.2 \mathrm{~kg}$ (1.2-7), respectively. Comprehensive stage II operation was performed at 4.5 months (2.9-39.5), and Fontan completion was established at 33.7 months (21.1-108.2). Operative and interstage mortality, morbidity, growth and reinterventions on the pulmonary arteries, and long-term operative results of the aortic arch reconstruction were assessed.

Results: Median follow-up time after Giessen hybrid stage I palliation was 4.6 years (0-16.8). Operative mortality at hybrid stage I, comprehensive stage II, and Fontan completion was $2.5 \%, 4.9 \%$, and $0 \%$, respectively. Cumulative interstage mortality was $14.2 \%$. At 10 years, the probability of survival is $77.8 \%$. Body weight $(<2.5 \mathrm{~kg})$ and aortic atresia had no significant impact on survival. McGoon ratio did not differ at comprehensive stage II and Fontan completion $(P=.991)$. Freedom from pulmonary artery intervention was estimated to be $32.2 \%$ at 10 years. Aortic arch reinterventions were needed in $16.7 \%$ of patients; 2 reoperations on the aortic arch were necessary.

Conclusions: In view of the early results and long-term outcome, the hybrid approach has become an alternative to the conventional strategy to treat neonates with hypoplastic left heart syndrome and variants. Further refinements are warranted to decrease patient morbidity. (J Thorac Cardiovasc Surg 2016;151:1112-23)

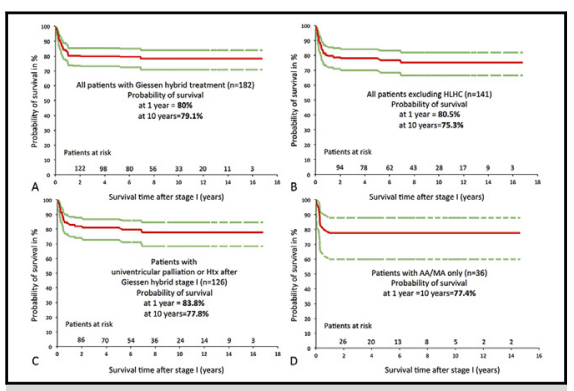

Probability of survival after the Giessen hybrid approach for different patient groups.

\section{Central Message}

The hybrid approach has become a reasonable alternative to the classic Norwood palliation for HLHS and variants.

\section{Perspective}

In view of the early results and long-term outcome after Giessen hybrid palliation, the hybrid approach has become a reasonable alternative to the conventional strategy to treat neonates with HLHS and variants. Further refinements are warranted to decrease patient morbidity.

See Editorial Commentary page 1123.

See Editorial page 909.
From the Pediatric Heart Center Giessen, Justus-Liebig-University, Giessen, Germany.

Read at the 95th Annual Meeting of The American Association for Thoracic Surgery, Seattle, Washington, April 25-29, 2015.

Received for publication April 23, 2015; revisions received Sept 29, 2015; accepted for publication Oct 8, 2015; available ahead of print Dec 15, 2015.

Address for reprints: Hakan Akintuerk, MD, Department of Congenital Heart Surgery, Pediatric Heart Center Giessen, Justus-Liebig University, Feulgenstrasse 10-12, 35385 Giessen, Germany (E-mail: can.yerebakan@med.uni-rostock.de). $0022-5223 / \$ 36.00$

Copyright $(\odot 2016$ by The American Association for Thoracic Surgery

http://dx.doi.org/10.1016/j.jtcvs.2015.10.066
The treatment of patients with hypoplastic left heart syndrome (HLHS) follows a well-established classic algorithm for most institutions worldwide. Recent

Scanning this QR code will take you to supplemental figure for this article. The AATS 2015 Webcast and discussion are available from the URL at the end of the article.

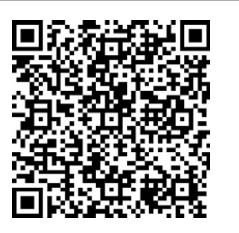



Abbreviations and Acronyms
$\mathrm{BPAB}=$ bilateral pulmonary artery banding
cMRI $=$ cardiac magnetic resonance imaging
HLHS $=$ hypoplastic left heart syndrome
Htx = heart transplantation
PTFE $=$ polytetrafluoroethylene

advances in perioperative care and steady refinements in operative techniques continue to result in improvement of short- and long-term outcomes of the classic Norwood palliation for these patients. ${ }^{1-3}$

The hybrid approach for HLHS and variants follows the same physiologic objectives as the classic Norwood procedure by alternative techniques in controlling pulmonary blood flow, whereas unobstructed systemic perfusion is maintained via an open arterial duct. This strategy involves off-pump bilateral pulmonary artery banding (BPAB) and interventional stenting (or continuous prostaglandin therapy) of the ductus arteriosus (ie, hybrid stage I) in the neonatal period. Therefore, the eventual performance of a Norwood-type palliation using cardiopulmonary bypass, which involves an aortic arch reconstruction including a superior cavopulmonary connection (ie, comprehensive stage II operation) or as indicated a biventricular correction, is deferred until the age of 4 to 8 months. Hybrid therapy has been proposed to overcome obvious drawbacks of the classic and widely adopted Norwood operation and aims to improve survival and outcome for these patients in a less-invasive way. First, a neonatal performance of a major surgical procedure using cardiopulmonary bypass with hypothermia is avoided; second, patients with borderline left ventricular structures may retain the potential to receive a biventricular correction 4 to 8 months later without compromising survival, postponing an immediate definitive decision in the newborn period in comparison with the classic Norwood palliation. ${ }^{4}$ However, there are substantial differences in the patient selection, operative and medical treatment strategies, and detailed further management of patients who undergo hybrid palliation with an impact on early and late outcomes. ${ }^{5-8}$ Indeed, the fact has to be emphasized that hybrid therapy for all types of HLHS has been applied in a standard manner in few institutions worldwide. ${ }^{3,9}$

In recent years, hybrid treatment has moved from a myth to an alternative modality in a growing number of institutions globally. Excellent surgical programs have reported similar outcomes with the performance of the hybrid procedure, which usually has been applied in high-risk patients in comparison with the classic Norwood palliation so far. ${ }^{6,8,10}$ Higher morbidity after hybrid treatment has been claimed as a result of $\mathrm{BPAB}^{7}$ and has raised concerns for an adequate pulmonary artery rehabilitation at the time of Fontan operation. ${ }^{6}$ Further critical comments followed immediately because of controversial results in the literature. ${ }^{11}$

At the Pediatric Heart Center Giessen, all types of HLHS and variants are treated with the modified Giessen hybrid strategy. Since 1998, 182 patients have received an initial Giessen hybrid stage I procedure. The aim of this article is to describe our operative results, the early and late mortality and morbidity with regard to pulmonary artery and aortic arch reinterventions, our detailed multidepartment strategy, and the long-term outcome of 118 patients with HLHS and variants who received the Giessen hybrid stage I procedure in a retrospective manner.

\section{PATIENTS AND METHODS}

The Ethics Committee of the Justus-Liebig-University Giessen approved this study. Between June 1998 and February 2015, 182 patients with the diagnosis of HLHS, hypoplastic left heart complex, and variants received an initial surgical BPAB in the Pediatric Heart Center Giessen (Giessen, Germany).

Among the group of 182 patients, a cohort of 41 patients who have been defined to have borderline/hypoplastic left ventricular structures and 7 patients with the initial diagnosis of HLHS were later amenable to receive a biventricular circulation after the hybrid stage I procedure. ${ }^{4}$ Comfort care was provided in 8 patients on the basis of a family decision to abandon any therapeutic measure. These 2 groups of patients were excluded from this study. Eight patients underwent heart transplantation (Htx) after BPAB/ ductal stenting. This study comprises 126 patients who were palliated with the Giessen hybrid stage I procedure for a univentricular palliation or primary Htx $(n=8)$. No patient was excluded because of complicated preoperative status, such as cardiopulmonary shock or syndromic features, without an explicit family decision. A classic Norwood operation was offered in the initial phase of the series for patients with aortic atresia and diminutive aortic arch, but this was abandoned because of the use of retrograde stents in such patients $(n=3$ in this series). A retrograde coarctation was managed by the insertion of a retrograde stent $(n=3)$ or a continuous prostaglandin infusion $(\mathrm{n}=2)$. The median age of patients at hybrid stage I was 6 days (0-237). The median weight at the hybrid stage I procedure was $3.2 \mathrm{~kg}(1.2-7)$.

Patient data have been gathered using a retrospective analysis of patient charts, discharge and operative reports, cardiopulmonary bypass reports, cardiac magnetic resonance imaging (cMRI), and heart catheterization for the outcome of aortic arch reconstruction. Because all patients were monitored with regular visits in our outpatient cardiology clinic, information on the long-term morbidity and mortality is available for the entire group. Operative mortality has been defined as 30-day mortality postoperatively. Interstage mortality is defined for patients who died between 30 days postoperatively and the following stage of palliation. Reinterventions were defined as any surgical or interventional procedure that was required for a cardiac or hemodynamic problem.

\section{Cardiac Magnetic Resonance Imaging}

Imaging was performed on a 3-T system (Magnetom Verio, software version syngo MR B 17, Siemens, Erlangen, Germany) with a 32-channel body coil. cMRI with the feasibility of adequate pulmonary artery measurements was available in 33 patients before comprehensive stage II and 24 patients before Fontan completion after the year 2008. Patients with stent artifacts were excluded.

To measure the dimensions of the pulmonary arteries, time-resolved, gadolinium-enhanced, 3-dimensional magnetic resonance angiography was obtained in the coronal plane with the following imaging parameters: repetition time $2.6 \mathrm{~ms}$, echo time $0.96 \mathrm{~ms}$, slice thickness $1.37 \mathrm{~mm}$, flip 
angle $19^{\circ}$, bandwidth $698 \mathrm{~Hz} /$ pixel, field of view $230 \times 350 \mathrm{~mm}^{2}$, matrix $256 \times 168$, and 1 signal average. Images were acquired after intravenous injection of a gadolinium-based contrast agent at a dose of $0.2 \mathrm{mmol} / \mathrm{kg}$ (Magnevist, Bayer Schering Pharma AG, Leverkusen, Germany) followed by a normal saline flush. Electronically saved magnetic resonance studies of the patients were reviewed. Two studies for each patient that had been performed before the comprehensive stage II operation and the performance of the total cavopulmonary anastomosis were included in the analysis. The diameters of the right and left pulmonary arteries were measured in the contrast-enhanced angiography images just before arborization in the lobar branches. The diameter of the aorta was measured at the level of the diaphragm to calculate the McGoon ratio for each patient from the sum of the pulmonary artery diameters divided by the diameter of the descending aorta. For the anesthesiologic management of our Giessen hybrid staged palliation, see Table E1. For cardiologic management of our Giessen hybrid staged palliation, see Table E2.

\section{Surgical Aspects of the Hybrid Stage I Operation}

Patient characteristics at hybrid stage I have been described by Schranz and colleagues. ${ }^{9}$ A median sternotomy followed by subtotal thymectomy and limited cranial pericardiotomy of 3 to $4 \mathrm{~cm}$ in length was performed. A pulmonary holding suture enabled unrestricted vision to both pulmonary arteries as needed. Two pieces of $3.5-\mathrm{mm}$ polytetrafluoroethylene (PTFE) tube were cut to approximately 1.5 to $2 \mathrm{~mm}$ in width $(<2.5 \mathrm{~kg}, 3$-mm PTFE bands). After a strictly limited preparation of the right pulmonary artery, the first band was placed by using a 6-0 Prolene suture, which was used to unite both ends of the band and the superior adventitial layer of the right pulmonary artery at the same time so that no additional suture was needed to prevent a displacement of the band. The same steps were applied for the left pulmonary artery after moving the pulmonary artery to the right side of the patient by using the holding suture. Episodes of supraventricular tachycardia could be terminated with drips of cold saline on the atria or antiarrhythmic medication as needed. The pericardial space was washed out with normothermic saline before closure of the pericardial space in that the pericardial ends were reapproximated completely with a running 6-0 polydioxanone suture to limit adhesions at the comprehensive stage II operation. A retrosternal 4-mm drainage was placed. By following these algorithms, intrapericardial adhesions did not complicate or prolong the comprehensive stage II operation.

\section{Surgical Aspects of the Comprehensive Stage II Operation}

The characteristics of the patients $(n=101)$ who underwent the comprehensive stage II operation, their operative data, and their concomitant procedures are shown in Table 1. Prosthesis-aided brachiocephalic trunk (and ductal cannulation if severe coarctation of the aorta is present), bicaval cannulation, and venting of the common atrium were instituted. Standard surgical procedures during the comprehensive stage II operation included bilateral pulmonary artery de-banding with patch augmentation or intraoperative balloon dilation of the pulmonary artery at the sites of the bandings, stent removal from the ductus arteriosus, patch augmentation of the aortic arch, atrioseptectomy, and bidirectional Glenn anastomosis. Pulmonary arteries were reconstructed using autologous or xenopericardium at the sites of the bilateral bandings as needed. In recent years, an intraoperative balloon dilation of the pulmonary arteries using 6to 8-mm balloon catheters seems adequate. Bidirectional Glenn anastomosis was performed on the beating heart using continuous 6-0 polydioxanone suture. Selective cerebral perfusion by a 3.5-mm PTFE prosthesis aided cannulation of the brachiocephalic trunk with moderate hypothermia at $26^{\circ}$ to $28^{\circ} \mathrm{C}$, which was instituted in $90 \%$ of the patients. Cardioplegic arrest of the heart was established using Bretschneider's cardioplegic solution (Custodiol HTK; Köhler Chemie GmbH, Bensheim, Germany) at a dose of $30 \mathrm{~mL} / \mathrm{kg}$ by selective direct cannulation of the ascending aorta after open filleting of the inner curvature of the aortic arch. Thereafter, the partial side-to-side proximal aortic and pulmonary artery anastomosis was
TABLE 1. Perioperative data and concomitant procedures at comprehensive stage II operation

Perioperative data at comprehensive stage II operation $\mathbf{n}=101(\mathbf{1 0 0} \%)$

Patient demographics

Age, mo

$4.5(2.9-39.5)$

Body weight, $\mathrm{kg}$

$5(4.4-9.4)$

Body surface area, $\mathrm{m}^{2}$

$0.3(0.2-0.42)$

Diagnosis

HLHS

AA/MA

30 (29.7)

AS/MS

$25(24.7)$

AA/MS

35 (34.6)

AS/MA

8 (7.9)

Other

$3(2.9)$

Operative data

CPB time, min

249 (162-397)

ACC time, min

69 (10-163)

SCP, $n$

$91(90)$

SCP, time, $\min$

$70(17-147)$

SMP, $\mathrm{n}$

SMP, time, min

$86(5-170)$

Postoperative ECMO therapy, $\mathrm{n}$

$5(4.9)$

Delayed sternal closure, $n$

$10(9.8)$

Post-CPB saturation, \%

77 (60-90)

Post-CPB CVP, mm Hg

Post-CPB PAP, mm Hg

$17(7-23)$

Concomitant procedures

ASD enlargement, $\mathrm{n}$

$101(100)$

$34 / 2 / 65$

LPA dilation/stent/reconstruction, $n$

$19 / 1 / 16$

RPA dilation/stent/reconstruction, $\mathrm{n}$

$5(4.9)$

TVR

Correction of cor triatriatum

Postoperative data

Intubation time, $\mathrm{d}$

$2(0-35)$

ICU time, $\mathrm{d}$

8 (1-47)

Hospital stay, d

$29(9-214)$

HLHS, Hypoplastic left heart syndrome; $A A$, aortic atresia; $M A$, mitral atresia; $A S$, aortic stenosis; $M S$, mitral stenosis; $C P B$, cardiopulmonary bypass; $A C C$, aortic crossclamp; $S C P$, selective cerebral perfusion; $S M P$, selective myocardial perfusion; $E C M O$, extracorporeal membrane oxygenation; $C V P$, central venous pressure; $P A P$, pulmonary artery pressure; $A S D$, atrial septal defect; $L P A$, left pulmonary artery; $R P A$, right pulmonary artery; TVR, tricuspid valve reconstruction; $I C U$, intensive care unit.

performed, followed by aortic arch reconstruction using a preformed curved pericardial xenopatch/conduit (BioIntegral Surgical, Inc, Mississauga, Canada) after complete removal of the ductal stent and ductal tissue. The toe of the patch augmentation was placed significantly beyond the isthmus region in the descending aorta. The xenograft was a commercially available curved xenopatch specifically designed for use in Norwood-type procedures. With the NoReact treatment (heparin-based proprietary detoxification and biomodification of glutaraldehyde-treated tissue that stabilizes tissue crosslinking and prevents release of aldehydes; BioIntegral Surgical, Inc.), this patch is free of calcification at Fontan completion.

\section{Surgical Aspects of the Fontan Operation}

Characteristics of the patients $(n=62)$, perioperative data, and concomitant procedures at comprehensive stage II operation are shown 
TABLE 2. Perioperative data and concomitant procedures at Fontan completion

\begin{tabular}{|c|c|}
\hline Perioperative data at Fontan completion, $n$ & $62(100 \%)$ \\
\hline \multicolumn{2}{|l|}{ Patient demographics } \\
\hline Age, mo & $33.7(21.1-108.2)$ \\
\hline Body weight, $\mathrm{kg}$ & $13(8.5-19.7)$ \\
\hline Body surface area, $\mathrm{m}^{2}$ & $0.56(0.4-0.79)$ \\
\hline \multicolumn{2}{|l|}{ Operative data } \\
\hline $\mathrm{CPB}$ time, $\min$ & $103.5(59-192)$ \\
\hline $\mathrm{ACC}, \mathrm{n}$ & $5(8)$ \\
\hline ACC time, $\min$ & $58(44-73)$ \\
\hline $\mathrm{SCP}, \mathrm{n}$ & $2(3.2)$ \\
\hline SCP, time, min & $34(23-45)$ \\
\hline SMP, $n$ & $1(1.6)$ \\
\hline SMP, time, $\min$ & 27 \\
\hline Postop ECMO therapy, $\mathrm{n}$ & $1(1.6)$ \\
\hline Delayed sternal closure, $\mathrm{n}$ & 0 \\
\hline Post-CPB saturation, $\%$ & $97.5(83-100)$ \\
\hline Post-CPB CVP1, mm Hg & $16(11-22)$ \\
\hline Post-CPB CVP2, mm Hg & $18(12-25)$ \\
\hline \multicolumn{2}{|l|}{ Concomitant procedures } \\
\hline \multicolumn{2}{|l|}{ Fenestration, $\mathrm{n}$} \\
\hline $4 \mathrm{~mm}$ & $31(50)$ \\
\hline $5 \mathrm{~mm}$ & $4(6.4)$ \\
\hline ASD enlargement & $2(3.2)$ \\
\hline VSD enlargement & $1(1.6)$ \\
\hline TVR & $4(6.4)$ \\
\hline MVR & $1(1.6)$ \\
\hline LPA balloon dilation/reconstruction & $6(9.6) / 9(14.5)$ \\
\hline RPA balloon dilation/reconstruction & $0 / 7(11.3)$ \\
\hline Aortic arch reconstruction & $2(3.2)$ \\
\hline Glenn takedown and $\mathrm{mBT}$ shunt & $1(1.6)$ \\
\hline Pacemaker implantation & $2(3.2)$ \\
\hline \multicolumn{2}{|l|}{ Postoperative data } \\
\hline Intubation time, $\mathrm{d}$ & $0(0-26)$ \\
\hline ICU time, $\mathrm{d}$ & $6(2-27)$ \\
\hline Hospital stay, d & $23(11-53)$ \\
\hline
\end{tabular}

$C P B$, Cardiopulmonary bypass; $A C C$, aortic crossclamp; $S C P$, selective cerebral perfusion; $S M P$, selective myocardial perfusion; $E C M O$, extracorporeal membrane oxygenation; $C V P 1$, upper central venous pressure; $C V P 2$, lower central venous pressure; $A S D$, atrial septal defect; $V S D$, ventricular septal defect; $m B T$, modified Blalock-Taussig; $T V R$, tricuspid valve reconstruction; $L P A$, left pulmonary artery; $R P A$, right pulmonary artery; $M V R$, mitral valve reconstruction; $I C U$, intensive care unit.

in Table 2. Significant venovenous collaterals were coil-embolized during the preoperative catheterization. Patients underwent operation with the use of cardiopulmonary bypass on mild hypothermia of $34^{\circ} \mathrm{C}$ and bicaval and aortic cannulation on a beating heart. After extensive mobilization of the right and left pulmonary arteries and the Glenn anastomosis, a 19-mm ring-enforced PTFE (Gore-Tex; WL Gore \& Associates Inc, Flagstaff, Ariz) tube was placed between the vena cava inferior and the inferior aspect of the right pulmonary using 5-0 Prolene suture. The Gore-Tex tube was beveled in a fashion so that the anastomosis on the right pulmonary artery was directed slightly to the left with the toe of the graft. A fenestration between the graft and the right atrium was created as needed. The indication for a fenestration was decided if elevated pulmonary artery pressures were greater than $15 \mathrm{~mm} \mathrm{Hg}$, especially together with a transpulmonary gradient (pulmonary artery pressure/left atrial pressure) greater than $7 \mathrm{~mm} \mathrm{Hg}$ or as secondary criteria more than mild atrioventricular valve regurgitation (after eventual repair) and mild ventricular dysfunction (eg, end-diastolic pressure $>12 \mathrm{~mm} \mathrm{Hg}$ ).

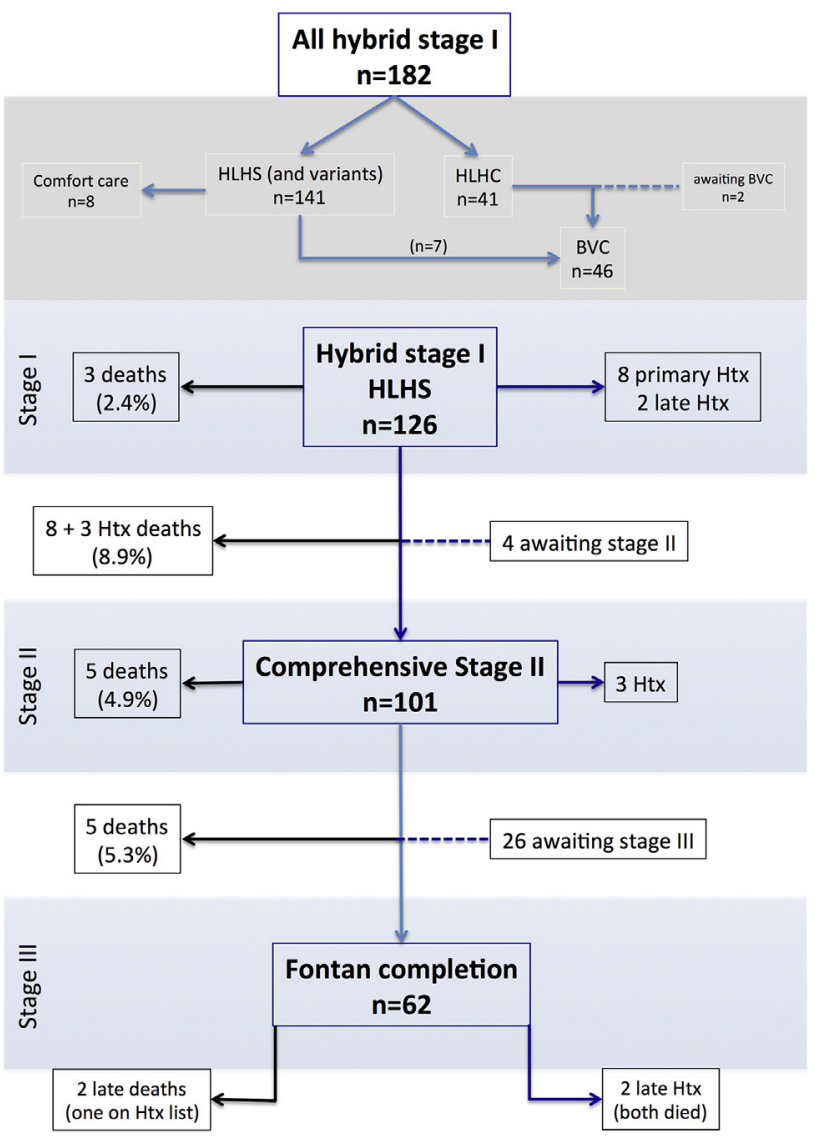

FIGURE 1. Three-stage hybrid palliation of all patients who underwent the Giessen hybrid stage I procedure. Absolute survival is shown, including operative and interstage deaths at each step of the palliative surgeries. $H L H S$, Hypoplastic left heart syndrome; HLHC, hypoplastic left heart complex; $B V C$, biventricular correction; Htx, heart transplantation.

\section{Statistical Analysis}

All data were stored and analyzed with SPSS version 15.0 (SPSS Inc, an IBM Company, Chicago, Ill). Descriptive statistics were computed for variables of interest. Data are presented as median (range) in most cases and otherwise specified. In dependence of distributions, the paired $t$ test or Mann-Whitney $U$ test was used for the comparisons within the groups between 2 time points. Actuarial survival and freedom from intervention after biventricular correction were calculated using the Kaplan-Meier equation.

\section{RESULTS}

Figure 1 shows a flow chart of the number of patients at different stages and operative and interstage deaths during hybrid palliation.

\section{Mortality}

Kaplan-Meier survival estimates for the different patient groups are depicted in Figures 2 and 3 and Figure E1. The median follow-up time after hybrid stage I palliation $(\mathrm{n}=126)$ is 4.6 years $(0-16.8)$. A comprehensive stage II operation still has to be performed in 4 patients, and Fontan 

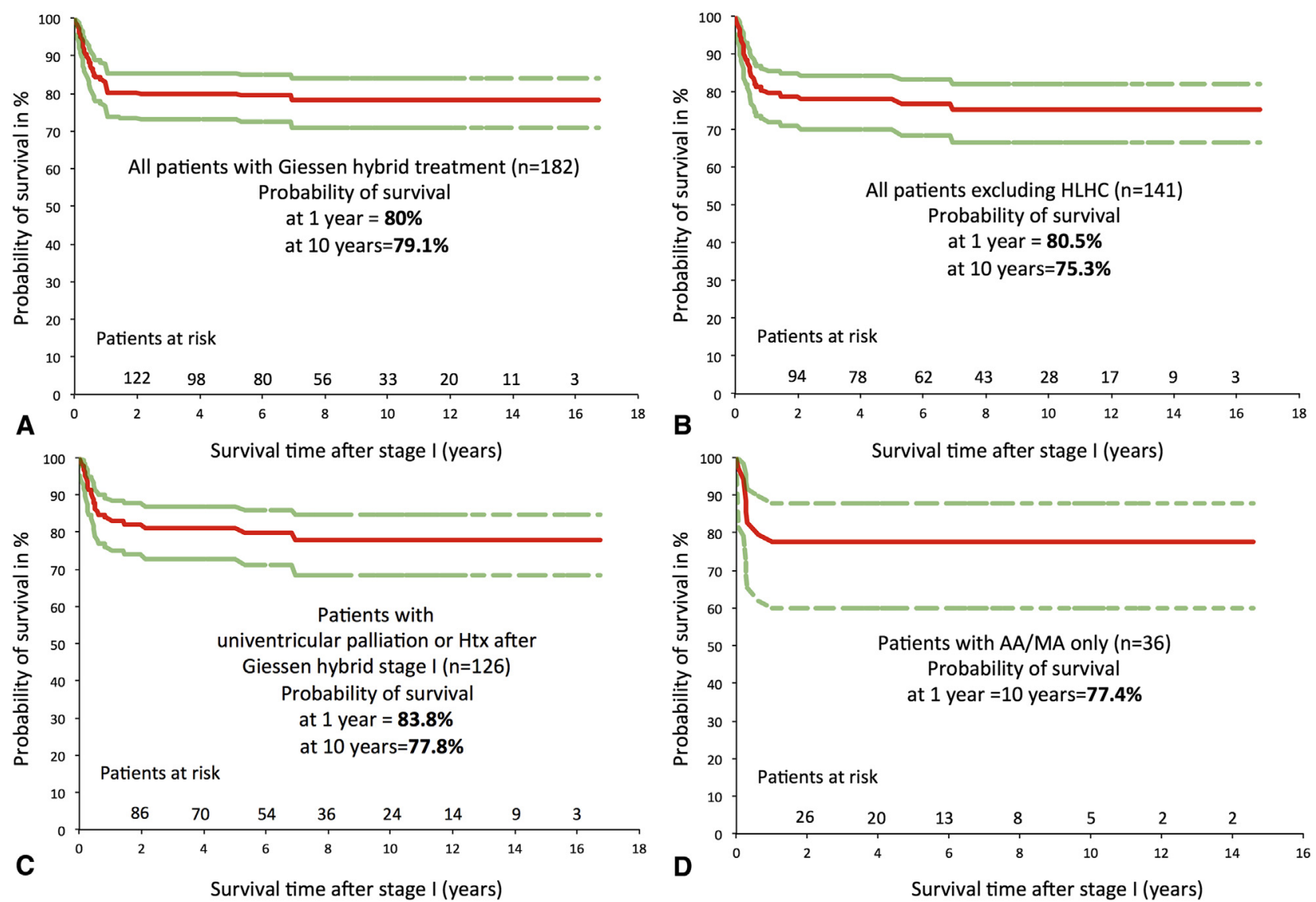

FIGURE 2. Probability of survival of patients after the Giessen hybrid stage I (red curves) and $95 \%$ confidence limits (green dotted curves). A, All patients $(\mathrm{n}=182)$ who underwent hybrid stage I. B, All patients excluding those with hypoplastic left heart complex $(\mathrm{n}=141)$. C, Patients with univentricular palliation or Htx after hybrid stage I $(\mathrm{n}=126)$. D, Patients with aortic atresia and mitral atresia $(\mathrm{n}=36)$. HLHC, Hypoplastic left heart complex; Htx, heart transplantation; $A A$, aortic atresia; $M A$, mitral atresia.

completion is planned in 26 patients. Two patients underwent Htx after hybrid stage I operation, and 3 patients underwent $\mathrm{Htx}$ after comprehensive stage II operation. These patients are alive.

Overall unadjusted cumulative operative and interstage mortality was $19 \%$ (24 patients) during 17 years of follow-up. Operative mortalities were $2.4 \%, 4.9 \%$, and $0 \%$ at hybrid stage I, comprehensive stage II operations, and Fontan completion, respectively. The estimated survival of all patients who underwent hybrid stage I procedure is $79.1 \%$ at 10 years follow-up. When patients who received biventricular repair were excluded, the 10 -year survival estimate is $75.3 \%$. Likewise, patients who were directed to univentricular palliation or Htx after Giessen hybrid stage I $(\mathrm{n}=126)$ had a survival estimate of $77.8 \%$ at 10 years follow-up. Birth weight $(<2.5$ vs $>2.5 \mathrm{~kg}$ ) had no significant impact on survival (Figure 3).

In addition, all 5 patients with HLHS and concomitant total anomalous pulmonary venous connection are most recently alive. Two patients underwent the Fontan operation, 1 patient underwent biventricular correction, and 2 patients are still awaiting the Fontan operation. ${ }^{12}$ Two patients received Htx late after Fontan completion and died in the follow-up. Two patients died (1 while on the list for Htx) late after the Fontan operation.

\section{Growth and Size of Pulmonary Arteries}

Growth of the pulmonary arteries has been retrospectively analyzed between the comprehensive stage II operation and the total cavopulmonary connection. Patients with stent artifacts were excluded. Figure $4, A$ to $C$ present the development of right and left pulmonary arteries with their absolute values and the McGoon ratios.

The absolute median diameter of the left pulmonary artery was $0.44 \mathrm{~cm}(0.26-0.89)$ before comprehensive stage II and increased to $0.52 \mathrm{~cm}(0.43-0.73)$ before Fontan completion. The absolute diameter of the right pulmonary artery increased from a median of $0.49 \mathrm{~cm}(0.29-0.79)$ before comprehensive stage II to $0.62 \mathrm{~cm}(0.40-0.81)$ before Fontan completion. Both changes were significant $(P<.001$ and $P=.012$ for the right and left pulmonary artery measurements, respectively). The calculated median 


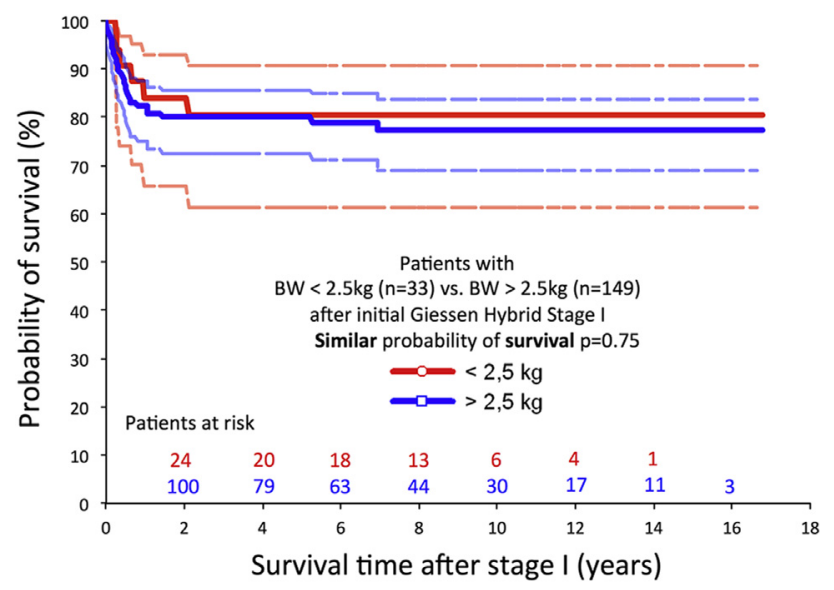

FIGURE 3. Impact of prehybrid stage I birth weight on long-term survival estimate. Probability of survival is shown for patients who weigh less than $2.5 \mathrm{~kg}$ (red curve) and more than $2.5 \mathrm{~kg}$ (blue curve) before Giessen hybrid stage I. Bright colored red and blue curves represent $95 \%$ confidence limits for babies who weigh less than $2.5 \mathrm{~kg}$ and more than $2.5 \mathrm{~kg}$, respectively. $B W$, Birth weight.

McGoon ratio did not differ significantly between comprehensive stage II operation and Fontan completion and was $1.26(0.76-2.44)$ and 1.22 (1.01-1.59), respectively $(P=.991)$.

\section{Morbidity}

Reinterventions on the pulmonary arteries after comprehensive stage II operation. Figure $4, D$ presents freedom from catheter intervention on the pulmonary arteries during the follow-up after comprehensive stage II operation. All interventions on the pulmonary arteries are catheter interventions. The interventions included nonselectively all procedures on the entire pulmonary artery stem and not only confined to the sites of pulmonary artery bandings. A total of 152 interventions in 64 patients were performed within 17 years. These interventions on both pulmonary arteries are as listed: stent left pulmonary artery $(n=84)$, only dilation left pulmonary artery $(n=39)$, only dilation right pulmonary artery $(n=24)$, and stent right pulmonary artery $(\mathrm{n}=5)$.

Freedom from pulmonary artery intervention at 1-year follow-up is $53.8 \%$ and decreases at 10 - and 15-year follow-ups to $32.2 \%$. When the rate of interventions was separately analyzed between the years of initial experience 1998 and 2007 in comparison with recent practice between 2008 and 2015, no significant difference in the total number and the probability of freedom from intervention was detected.

Outcome of aortic arch reconstruction at the comprehensive stage II operation. The outcome of aortic arch reconstruction was separately analyzed for all patients $(n=126)$ and for patients who received the same curved aortic patch by the same surgeon at comprehensive stage II operation. A reintervention on the aortic arch was needed in 21 patients $(16.7 \%)$. These consisted of 12 balloon dilations, 12 stent implantations, and 2 reoperations. Patients who underwent operation using the same patch by the same surgeon $(n=46)$ had a median age of 126 days (86-432), and their median weight was $5.0 \mathrm{~kg}$ (2.8-8.8) at comprehensive stage II operation. In this group, 6 patients $(13 \%)$ already had a catheter intervention on the aortic arch for redilation of ductal stents preoperatively. During the median follow-up of 25 months (0.3-105), 9 patients $(19.6 \%)$ developed a restenosis $(67 \%)$ on the distal aortic arch requiring a reintervention. Five patients required balloon dilation only, and 4 patients were treated with an additional stent placement after a median follow-up of 8 months (5-67). The use of the curved porcine xenograft for the aortic arch reconstruction resulted in a noncalcified aortic arch, which eased the surgical preparation and cannulation at the Fontan completion in comparison with homograft and pericardial patch materials that were used previously. Before 2004, we used a high number of aortic and pulmonary homografts for aortic reconstruction and were faced with the problem of extensive calcifications during the Fontan completion.

\section{DISCUSSION}

The hybrid strategy for the treatment of HLHS and variants has evolved from a niche therapy to a reasonable alternative for selected patients in a growing number of centers. The outcomes range from bad to excellent for both univentricular and biventricular pathways in the management of a wide spectrum of pathologies with small left heart structures. This collaborative approach has unique advantages so it is accepted as the standard of care in few institutions worldwide. $9,13,14$

The hybrid approach aims to control pulmonary blood flow by restriction via BPAB and maintain systemic perfusion through an open duct by the insertion of a ductal stent or continuous prostaglandin therapy. As with the treatment and outcome of other complex congenital heart disease, the hybrid treatment possesses substantial differences between different institutions in a nonstandardized manner. There are uncountable variations in patient selection, timing and sizing of the BPAB, and timing and techniques of subsequent ductal stenting. Furthermore, crucial aspects of interstage management are frequently unclear in the published literature. This retrospective analysis aimed to elucidate our detailed operative results of 3-stage hybrid palliation, collaborative interdepartmental strategy, and follow-up management in the hybrid treatment of HLHS.

Our series of 182 patients began in 1998 based on the "hybrid" idea of Gibbs and colleagues, ${ }^{15}$ and early promising results have been published. ${ }^{14}$ Similar success 

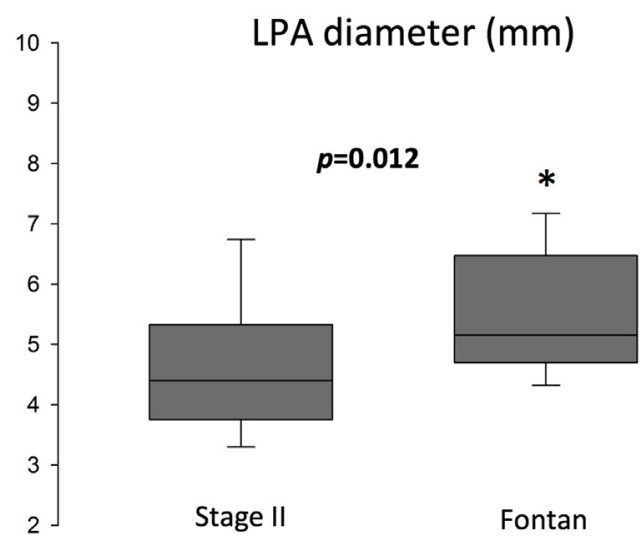

A
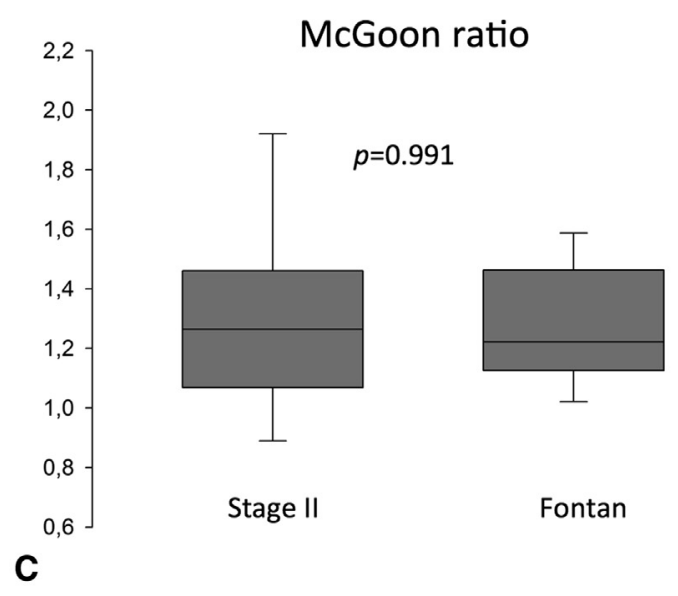

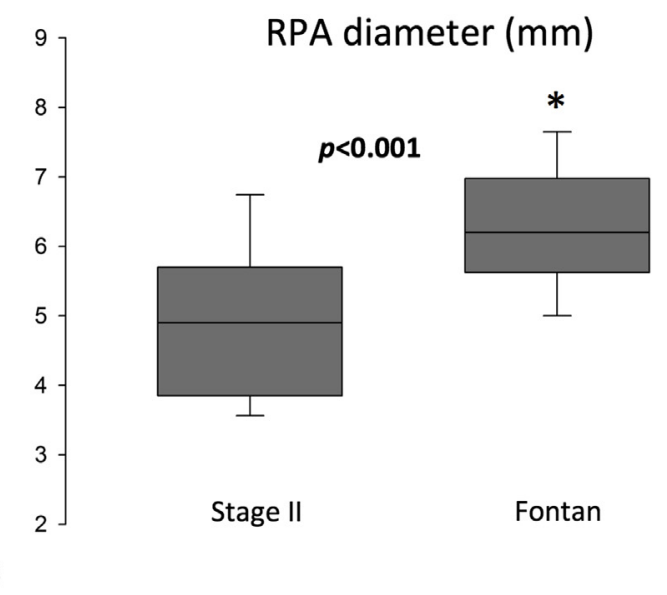

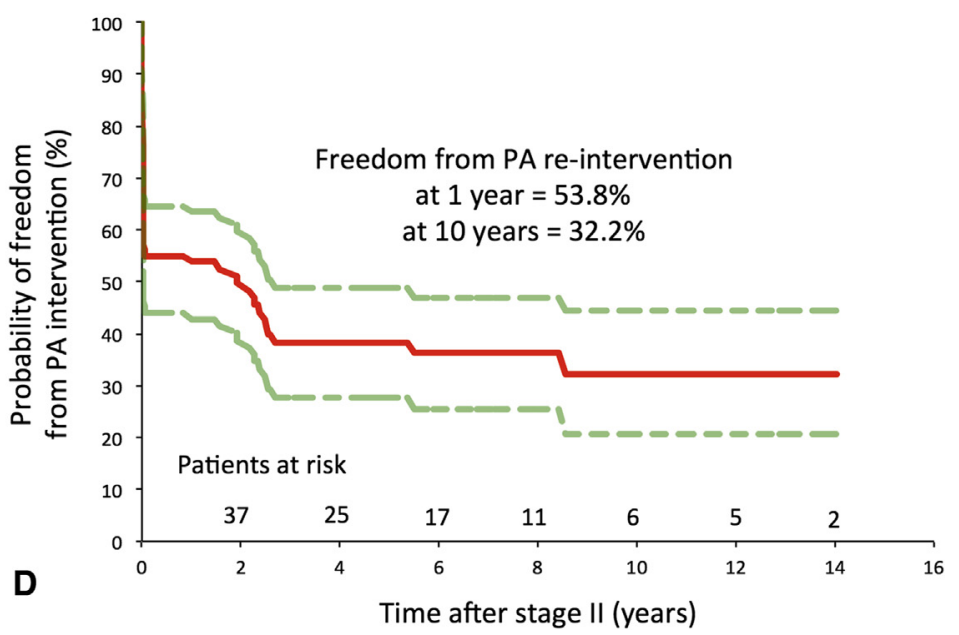

FIGURE 4. A-C, Box plots comparing pulmonary artery sizes before comprehensive stage II and before Fontan completion and McGoon ratio. D, Kaplan-Meier estimate of freedom from catheter reintervention on the pulmonary arteries (red curve) with corresponding 95\% confidence limits (green dotted curves). ${ }^{*} P<.05$. LPA, Left pulmonary artery; $R P A$, right pulmonary artery; $P A$, pulmonary artery.

rates have been confirmed by Galantowicz and colleagues ${ }^{3}$ in leading institutions for hybrid therapy in the United States. Encouraged by this early success, hybrid treatment became a standard for all patients with HLHS and variants in our institution that resulted in the first large series published in 2007. ${ }^{16}$ In the beginning of the experience, several advantages of the hybrid procedure became obvious for the entire team. First, well-known deleterious effects of a neonatal application of cardiopulmonary bypass could be avoided. A growing number of reports confirmed substantial relationships between the neurocognitive development and the use of a neonatal cardiopulmonary bypass. ${ }^{17,18}$ Second, the early mortality of the Giessen hybrid stage I procedure in an unselected patient population was exceedingly low $(1 \%-2 \%)$ in comparison with our own small classic Norwood series and the experience of other excellent institutions. ${ }^{19}$ Third, we were allowed time to make the strategic decision for patients with borderline left ventricular structures to pursue the univentricular or biventricular pathway; namely, an initial hybrid approach with BPAB and ductal stenting might be performed without the need for an early decision and major surgery. ${ }^{14}$ Indeed, by the year 2014, we have reported on 40 patients with borderline left ventricular structures who received a biventricular correction after the Giessen hybrid stage I procedure. The long-term outcome of these patients is highly favorable with approximately $90 \%$ survival after 10 years of follow-up. ${ }^{4}$

\section{Survival}

In this series of 126 patients, the operative mortality remained $2.4 \%$ for stage I. Together with the interstage I and II mortality of $8.9 \%$, approximately $90 \%$ of the patients were alive at the comprehensive stage II operation, which revealed $4.9 \%$ operative mortality and low postoperative morbidity. Only 5 deaths (5.3\%) occurred between stage II and Fontan completion. At 10-year follow-up, Kaplan-Meier estimated survival for 
the whole group reached $77.8 \%$ and was marginally influenced to $75.3 \%$ by the inclusion of patients who were directed to comfort care, biventricular correction. These results are similar to those in dedicated institutions with sustained expertise in hybrid treatment for HLHS. ${ }^{3}$ In comparison, the report of Pediatric Heart Network revealed $64 \%$ versus $74 \%$ transplant-free survival for the outcome of the classic Norwood operation and the Sano modification at 12 months follow-up, respectively. ${ }^{1}$ All patients with HLHS and total anomalous pulmonary venous connection are alive, although inferior outcome has been reported for these patients. ${ }^{20}$

Survival of the patients who undergo hybrid treatment is highly dependent on a strict collaboration among departments of pediatric cardiology, anesthesia, and congenital cardiac surgery. Fundamental details to our multidepartmental approach leading to satisfying outcome are presented in Table E1 and Table E2.

\section{Pulmonary Artery Reinterventions}

Bilateral banding of the pulmonary arteries is still a highly discussed issue with regard to the goal of sufficient pulmonary artery architecture at Fontan completion. In the presented series, we have analyzed pulmonary artery growth between comprehensive stage II and Fontan completion in the cMRI because our patients did not receive standard cardiac catheterization before the comprehensive stage II operation. The fact that a degree of poststenotic dilation after pulmonary artery banding may occur is known, but was not included in our results. The reconstruction of the pulmonary arteries was challenging at the comprehensive stage II operation in the beginning of our series. However, in recent years by conveying our hybrid approach to the operating room and implementing intraoperative balloon dilation of the pulmonary arteries, these challenges were partly overcome. When measured diameters of the pulmonary arteries in this are analyzed, we may have underestimated the absolute values; however, this is a given fact for the whole group. The main information remains the adequate growth of both the pulmonary arteries and stable McGoon ratio between the 2 measurements. The early and late surgical outcomes of our patients after the Fontan completion demonstrate the successful rehabilitation of the pulmonary arterial system in this series.

The described technique of bilateral pulmonary banding and our standard size of bands might have a positive impact on a still lower need for intervention in comparison with other reports. ${ }^{6}$ Our patients underwent a considerable number of catheter interventions in the follow-up; however, a considerable number of interventions were needed for a redilation of dilatable stents in the pulmonary arteries up to 16 to $18 \mathrm{~mm}$ in size. As anticipated, there were more interventions on the left pulmonary artery than on the right pulmonary artery because of the Glenn anastomosis with desired enlargement on the right banding site. The freedom from pulmonary artery reintervention is comparable to series after classic Norwood palliation with freedom from reoperation/reintervention rates at approximately $50 \%$ at 10 years. $^{6,21}$ A slight change in our intraoperative technique for pulmonary artery reconstruction by using less and smaller patches for reconstruction has reduced the need for early postoperative stenting for pulmonary artery branch thrombosis. Whether a more aggressive approach by operative reconstruction of the pulmonary arteries after comprehensive stage II rather than stenting would minimize the number of interventions and its impact on survival cannot be answered with the existent data. The risk of a pulmonary artery intervention did not differ between our early experience when we performed intraoperative pulmonary artery reconstruction with autologous or xenopericardial patches and recent years when an increasing number of intraoperative balloon dilations were used. Furthermore, stents were removed partially or totally from the pulmonary arteries during the Fontan operation as needed, allowing stent-in-stent placement with expansion to adult size. An adequate rehabilitation of the left pulmonary artery plays a crucial role in the outcome of the patients. Therefore, the liberalized application of cMRI contributes to an early and precise diagnosis of potential problems on the pulmonary arteries preventing radiation and providing less invasiveness in comparison with other diagnostic tools.

\section{Aortic Arch Reconstruction}

Aortic arch reconstruction including stent removal from the ductal-aortic junction does not create additional surgical risks during a comprehensive stage II operation. We usually perform BPAB first, which is followed by ductal stenting in the catheterization laboratory via a femoral approach. The main reason for this alternative approach is to delineate the highly variable anatomy of the aortoductal junction in the catheterization laboratory instead of in the operating room. An advantage of this approach is to actively prevent inadvertent placement of the ductal stent too far into the descending aorta.

The analysis of reinterventions on the aortic arch for all patients revealed a reintervention rate of $16.7 \%$. Two patients required a reoperation in the entire group. When the subgroup of patients who received an implant of a curved xenograft patch material by the same surgeon were analyzed, 9 patients developed a mild narrowing in the distal aortic arch, which was treated solely with interventional balloon dilation $(\mathrm{n}=5)$ or occasionally additional stenting $(\mathrm{n}=4)$. No patient required a reoperation in this subgroup. In both cases, the rate of this complication remains in the range of its occurrence with the classic Norwood operation without the interdigitating 
technique. ${ }^{22,23}$ A larger proportion of these patients are in our early experience when the technique of aortic arch reconstruction was different in that the tissue in the region of narrowed isthmus was not resected completely but rather patched after open filleting the aorta. The curved xenograft was always free of calcification during the Fontan operation and could be easily cannulated in a standard manner.

This report did not analyze the neurodevelopmental outcome of the cohort. This will be one of the most important determinants for a wider acceptance of the hybrid strategy. We continue to have a low incidence of neurologic problems, especially by using protective methods such as antegrade selective cerebral perfusion with intraoperative continuous monitoring aided by cranial and somatic near-infrared spectroscopy for all of our patients. Unpublished results of an ongoing multi-institutional study (Giessen, Germany and Zurich, Switzerland) with regard to neurocognitive outcome comparing the classic Norwood operation and hybrid approach are highly promising in favor of the hybrid procedure. Other investigators sought to answer this question and found no significant differences with regard to neurodevelopmental outcome between the Norwood procedure and hybrid treatment. ${ }^{10}$ Impaired cerebral perfusion has been reported after the hybrid stage I procedure. ${ }^{7}$ However, as mentioned earlier, because of differing techniques and the low number of patients in Saiki and colleagues' hybrid treatment, ${ }^{7}$ these results are not directly applicable to our cohort. Prospective, randomized studies are needed to enlighten this particular issue.

\section{CONCLUSIONS}

The hybrid strategy for patients with HLHS emerges as an alternative to conventional strategy with the neonatal performance of a Norwood-type palliation. The advantages of this approach are avoiding a neonatal major surgery including cardiopulmonary bypass without compromising but potentially improving the survival of these patients. Further refinements seem necessary to decrease the need for pulmonary artery interventions and would lead to less-complicated pulmonary artery rehabilitation and possibly better overall results. Neurodevelopmental outcome of the patients has to be investigated in the future and will be the leading determining factor in the value of hybrid treatment for HLHS.

Our experience suggests the following key factors in achieving a favorable outcome in hybrid therapy. First, there should be intense perioperative and postoperative collaboration with anesthesiology and pediatric cardiology by precise individual risk stratification of the patients. Second, standards should be implemented in all participating departments for the management in all stages, particularly for out-of-hospital follow-up. Third, there should be liberalized indication for the use of cMRI before comprehensive stage II and Fontan completion as needed.

\section{Study Limitations}

The limitations of the study are its retrospective design and short duration of the median follow-up of approximately 5 years even when the single-center experience is more than 15 years. Therefore, the question of whether our patients profit from hybrid treatment in the long-term cannot be fully answered. cMRI was reassessed from original but electronically saved sequences. Only a limited number of cMRI images were included because of late availability of our own cMRI after the year 2008 and average image quality in some patients with stented pulmonary arteries, which were excluded from the analysis. The measurement of the pulmonary artery diameter using cMRI is a valid method but not without limitation. We may have underestimated the absolute values of the pulmonary arteries, but if a systematic error has been instituted, this is true for all measurements. Therefore, we would recommend a focus on the growth of the diameters rather than on the absolute values of the pulmonary arteries.

\section{Conflict of Interest Statement}

Authors have nothing to disclose with regard to commercial support.

You can watch a Webcast of this AATS meeting presentation by going to: http://webcast.aats.org/2015/Video/ Tuesday/04-28-15_6A_1400_Yerebakan.mp4.

\section{References}

1. Ohye RG, Sleeper LA, Mahony L, Newburger JW, Pearson GD, Lu M, et al. Comparison of shunt types in the Norwood procedure for single-ventricle lesions. N Engl J Med. 2010;362:1980-92.

2. Iannettoni MD, Bove EL, Mosca RS, Lupinetti FM, Dorostkar PC, Ludomirsky A, et al. Improving results with first-stage palliation for hypoplastic left heart syndrome. J Thorac Cardiovasc Surg. 1994;107:934-40.

3. Galantowicz M, Cheatham JP, Phillips A, Cua CL, Hoffman TM, Hill SL, et al. Hybrid approach for hypoplastic left heart syndrome: intermediate results after the learning curve. Ann Thorac Surg. 2008;85:2063-70.

4. Yerebakan C, Murray J, Valeske K, Thul J, Elmontaser H, Mueller M, et al. Long-term results of biventricular repair after initial Giessen hybrid approach for hypoplastic left heart variants. J Thorac Cardiovasc Surg. 2015;149:1112-20.

5. Baba K, Kotani Y, Chetan D, Chaturvedi RR, Lee KJ, Benson LN, et al. Hybrid versus Norwood strategies for single-ventricle palliation. Circulation. 2012;126: S123-31.

6. Davies RR, Radtke WA, Klenk D, Pizarro C. Bilateral pulmonary arterial banding results in an increased need for subsequent pulmonary artery interventions. J Thorac Cardiovasc Surg. 2014;147:706-12.

7. Saiki H, Kurishima C, Masutani S, Tamura M, Senzaki H. Impaired cerebral perfusion after bilateral pulmonary arterial banding in patients with hypoplastic left heart syndrome. Ann Thorac Surg. 2013;96:1382-8.

8. Pizarro C, Davies RR, Woodford E, Radtke WA. Improving early outcomes following hybrid procedure for patients with single ventricle and systemic outflow obstruction: defining risk factors $\uparrow$. Eur J Cardiothorac Surg. 2015;47: 995-1000.

9. Schranz D, Bauer A, Reich B, Steinbrenner B, Recla S, Schmidt D, et al. Fifteen-year single center experience with the "Giessen Hybrid" approach for hypoplastic left heart and variants: current strategies and outcomes. Pediatr Cardiol. 2015;36:365-73. 
10. Knirsch W, Liamlahi R, Hug MI, Hoop R, von Rhein M, Pretre R, et al. Mortality and neurodevelopmental outcome at 1 year of age comparing hybrid and Norwood procedures. Eur J Cardiothorac Surg. 2012;42:33-9.

11. Hosseinpour AR. The questionable role of the hybrid procedure. Eur $J$ Cardiothorac Surg. 2015;47:1001-2.

12. Schranz D, Jux C, Akintuerk H. Novel catheter-interventional strategy for intracardiac connecting of total anomalous pulmonary venous return in newborns with hypoplastic left heart-syndrome prior to hybrid approach. Catheter Cardiovasc Interv. 2013;82:564-8

13. Galantowicz M. In favor of the hybrid stage 1 as the initial palliation for hypoplastic left heart syndrome. Semin Thorac Cardiovasc Surg Pediatr Card Surg Annu. 2013;16:62-4.

14. Akintuerk H, Michel-Behnke I, Valeske K, Mueller M, Thul J, Bauer J, et al. Stenting of the arterial duct and banding of the pulmonary arteries: basis for combined Norwood stage I and II repair in hypoplastic left heart. Circulation. 2002; 105:1099-103.

15. Gibbs JL, Wren C, Watterson KG, Hunter S, Hamilton JR. Stenting of the arterial duct combined with banding of the pulmonary arteries and atrial septectomy or septostomy: a new approach to palliation for the hypoplastic left heart syndrome. Br Heart J. 1993;69:551-5.

16. Akinturk H, Michel-Behnke I, Valeske K, Mueller M, Thul J, Bauer J, et al. Hybrid transcatheter-surgical palliation: basis for univentricular or biventricular repair: the Giessen experience. Pediatr Cardiol. 2007;28:79-87.

17. Licht DJ, Shera DM, Clancy RR, Wernovsky G, Montenegro LM, Nicolson SC, et al. Brain maturation is delayed in infants with complex congenital heart defects. J Thorac Cardiovasc Surg. 2009;137:529-36.

18. Mahle WT, Tavani F, Zimmerman RA, Nicolson SC, Galli KK, Gaynor JW, et al. An MRI study of neurological injury before and after congenital heart surgery. Circulation. 2002;106:I109-14.

19. Williams DL, Gelijns AC, Moskowitz AJ, Weinberg AD, Ng JH, Crawford E, et al. Hypoplastic left heart syndrome: valuing the survival. J Thorac Cardiovasc Surg. 2000;119:720-31.

20. Sinzobahamvya N, Arenz C, Reckers J, Photiadis J, Murin P, Schindler E, et al. Poor outcome for patients with totally anomalous pulmonary venous connection and functionally single ventricle. Cardiol Young. 2009;19:594-600.

21. Griselli M, McGuirk SP, Ofoe V, Stumper O, Wright JG, de Giovanni JV, et al. Fate of pulmonary arteries following Norwood procedure. Eur J Cardiothorac Surg. 2006;30:930-5.

22. Bautista-Hernandez V, Marx GR, Gauvreau K, Pigula FA, Bacha EA, Mayer JE Jr, et al. Coarctectomy reduces neoaortic arch obstruction in hypoplastic left heart syndrome. J Thorac Cardiovasc Surg. 2007;133:1540-6.

23. Lamers LJ, Frommelt PC, Mussatto KA, Jaquiss RD, Mitchell ME, Tweddell JS. Coarctectomy combined with an interdigitating arch reconstruction results in a lower incidence of recurrent arch obstruction after the Norwood procedure than coarctectomy alone. J Thorac Cardiovasc Surg. 2012;143:1098-102.

Key Words: hypoplastic left heart syndrome, hybrid treatment, survival, outcome, pulmonary arteries, reinterventions

\section{Discussion}

Dr Galantowicz (Columbus, Ohio). I thank the Association for the opportunity to discuss this important article. Yerebakan and colleagues are to be congratulated for excellent results and outcomes but also an important contribution to our field. Moreover, I and the rest of the Columbus team thank the Giessen team for their ongoing collaborative spirit over these past 15 years. Since we discovered each other independently working on this concept of a hybrid approach, we've shared much information.

I was struck in reading your article how similar our experiences have been in terms of numbers and outcomes. We have 190 patients so far, with 140 through the second stage and 70 through the Fontan, and the overall outcomes are almost identical to yours, I think, which validates the concept that this has emerged from a myth to truly an alternative for these complex patients. I encourage the audience to read this excellent article. It is full of details on the interdisciplinary multi-aspect protocols that were used by their team in the perioperative and interstage periods.

I have 4 questions: We, too, found that a size less than $2.5 \mathrm{~kg}$ does not affect outcomes. As you know, your approach is a little different at the hybrid stage I than ours is. Do you do anything differently in the very small infants, specifically the stenting, is it still percutaneous?

Dr Yerebakan. No. The difference is that we use a band size of $3.0 \mathrm{~mm}$ in patients who weigh less than $3.0 \mathrm{~kg}$. This is the first difference in a newborn with normal weight. The second is probably in comparison with your excellent approach. We do the stenting in the catheterization laboratory after $\mathrm{BPAB}$, because in the beginning of our experience we had some bad results with stent dislocation in the operating room. To quote Dr Schranz, the aortoductal junction in every patient has a different anatomy like faces in this audience. I think this may play a role. Other than this, there are no significant differences between the patients.

Dr Galantowicz. The next 2 questions have to do with the left pulmonary artery. Later in your experience you shifted from left pulmonary artery reconstruction to intraoperative ballooning of the left pulmonary artery. As you know, there is a difference in the compliance and wall proximal and distal to the band after we move it. I would suspect that puts some risk in the distal pulmonary artery with balloon dilatation. Did you have any complications, rupture or bleeding or otherwise, with that technique?

Dr Yerebakan. Actually not in a large number of patients. There were 1 or 2 intraoperative dissections of the intima, which was not a big deal and was handled with stenting of the left pulmonary artery. Other than this, in the last few years, we have always used an intraoperative balloon dilation, using 6- to 8-mm balloons, and this has created similar results that are not shown in this presentation but have been analyzed. That means in our early experience with more reconstructions on the pulmonary artery using pericardial patches versus the balloon dilation, there is actually no significant difference with regard to reinterventions on the pulmonary artery after these procedures, after comprehensive stage II. I think the numbers are still too low to conclude a statement on this.

Dr Galantowicz. In follow-up in that concept, in the article you described, and I think it was on the slide as well, $100 \%$ of patients at the comprehensive stage II received some intervention on the left pulmonary artery with no difference whether there was late reintervention, and then approximately $90 \%$ wound up with a left pulmonary artery stent late. 
My question really has to do more with that the left pulmonary artery seems to be more at risk in children with HLHS. It probably starts in utero with the space being compromised by the enlarged ductus and so on. Should we be moving away from trying to surgically grow this pulmonary artery and just go right to pulmonary artery stenting, left pulmonary artery stenting, in $100 \%$ of patients at the second-stage procedure?

Dr Yerebakan. It's hard to answer. At least my data wouldn't give you an idea on that. We are, as you know, liberal on putting stents or performing interventional procedures on the left pulmonary artery. No patient has received an operation because of problems on the left pulmonary artery in our series. That doesn't mean that the left pulmonary artery isn't compromised; it only means that we do not prefer operations on the left pulmonary artery early or late in these patients.

We have to admit that the pulmonary arteries in the hybrid approach are still a problem, especially the left pulmonary artery, because the right one is handled with the Glenn anastomosis in the second stage. I think the crucial point is the early detection of the problems on the left pulmonary artery, either early postoperatively in the intensive care unit or later on with follow-up visits of the patients and liberal use of magnetic resonance imaging; for instance, in our center we use magnetic resonance imaging for all patients who undergo a stage II operation and as needed in the interstage period and solution of the problem. Whether the operation or stent implantation is the correct means of treating left pulmonary artery problems, I'm not able to answer with the existent data.

Dr Galantowicz. You have a unique population in that you have $100 \%$ follow-up as a regional center in all these patients. Some of the potential benefits of this approach are not only to the individual but also to the family, for example, days of work missed, or even to society in terms of resource use, cost of care. Do you have any other types of outcome measures that go beyond the individual for your cohort of patients?

Dr Yerebakan. If I understand your question correctly, do we have other outcome parameters showing our results?

Dr Galantowicz. That go beyond the individual patient. So for example, total dollars or total Euros spent in the care of these children.

Dr Yerebakan. No, I don't have these data.

Dr C. Caldarone (Toronto, Ontario, Canada). I always look forward to a report from Giessen pioneering the hybrid approach. This is kind of a general question, and you may not be able to answer, but no matter how we manage patients with single ventricles, there is this vexing $20 \%$ or so mortality early after our first palliation, whether it be Norwood or hybrid. It's very similar in both modalities despite different operations. Why are your patients dying after a stage I procedure, and is that mode of death different than you might expect after a Norwood procedure? This is crucial, because if you can identify a different mode of death, you may be able to make some intervention to prevent that.

Dr Yerebakan. This is an important question, and I think there is a different mode of deaths after stage I. The stage I procedure is a procedure that can be performed by everyone with good results. This is a simple procedure.

I have not shown further details of our management strategy, which begins from the admittance of the patients in our center to discharge after stage I procedure, but you can read this in the article. This is a collaborative approach. The surgery itself is not a big problem. We have seen in our results that the stage I procedure has a procedural mortality of approximately $3 \%$. One was in our early experience with intraoperative mortality during banding, one was displacement of the stent, and since 2001 we have not lost any patients after the stage I procedure or in the interstage period. Two patients in the interstage period had severely compromised ventricular function that we could not recover, and they received heart transplants. But other patients probably died at home as the result of a long or missed interstage follow-up in the early phase of our experience. So if you do a strict follow-up on these patients, which is weekly after stage I in our center right now, it's highly improbable to lose patients between stage I and II. We do not exclude any patients from the hybrid treatment, which means that we would not exclude patients who come into the clinic after resuscitation or have high lactate. We follow a strict regimen. If you follow this regimen, it's highly improbable.

But you're right, patients die. We have to analyze this further to decrease mortality. Our main problem with these patients is, as you see, the morbidity. The mortality, I think is promising at least after 10 years.

Dr E. Bacha (New York, NY). Back to the stenting in the less than $2.5-\mathrm{kg}$ babies. So you're saying they go through a groin stick, a femoral arterial stick, the interventional cardiologist, and do you not think that can jeopardize the leg in those less than $2.5-\mathrm{kg}$ babies? I mean, at least our cardiologist would be worried about that.

Dr Yerebakan. We don't have any problems with that. I'm not a cardiologist, so I cannot tell you any details of that.

Dr Bacha. I know. But at least at our center that would be a reason not to proceed with percutaneous stenting.

Dr Yerebakan. Yes.

Dr Bacha. So next quick question, the bands that you place, do you actually fix them in place?

Dr Yerebakan. We do.

Dr Bacha. You do fix them in place.

Dr Yerebakan. The banding.

Dr Bacha. Okay, that's good. The third question is retrograde coarctation, you haven't mentioned anything 
about that. Is that still a problem in your hands? Do you worry about it, or do you not?

Dr Yerebakan. This is indeed a problem, but we don't worry about that. This is a problem for all people; however, this is not a frequent problem. There are some patients who have this. We have 2 strategies to handle these patients, one is to band them, give them prostaglandin for a longer time, and wait until stage II.

Dr Bacha. So who is the typical patient you will do that strategy in, you would not band the duct?

Dr Yerebakan. For example, a patient who has a obstruction toward the aortic arch.

Dr Bacha. But they're on prostaglandin E by definition at the time when you see them, so you don't necessarily know that they have a retrograde obstruction of the arch. Right? How do you diagnose that obstruction toward the arch?

Dr Yerebakan. After pulmonary arterial banding, these patients come to the intensive care unit before ductal stenting and we have 2 side arterial monitoring, a right radial artery and femoral artery. You can see in the arterial measurements whether there is a problem toward the arch. Second, you can apply a Doppler on the brachiocephalic trunk and see if there is a retrograde problem. Third, the ventricular function on transthoracic echocardiography will give you another hint whether they have a problem in the perfusion of the coronaries or the head vessels.

\title{
EDITORIAL COMMENTARY
}

\section{Hybrid therapy for hypoplastic left heart syndrome: Myth, alternative, or standard-neither Minotaur nor Midas}

\author{
Ralph S. Mosca, MD
}

From the Department of Cardiothoracic Surgery, New York University Langone Medical Center, New York, NY. Disclosures: Author has nothing to disclose with regard to commercial support.

Received for publication Oct 26, 2015; accepted for publication Oct 27, 2015; available ahead of print Dec 15, 2015.

Address for reprints: Ralph S. Mosca, MD, Department of Cardiothoracic Surgery, New York University Langone Medical Center, 530 First Ave, Suite 9V, New York, NY 10016 (E-mail: ralph.mosca@nyumc.org).

J Thorac Cardiovasc Surg 2016;151:1123-5 $0022-5223 / \$ 36.00$

Copyright (c) 2016 by The American Association for Thoracic Surgery http://dx.doi.org/10.1016/j.jtevs.2015.10.099

The development of a hybrid procedure for palliation of hypoplastic left heart syndrome (HLHS) was prompted by limited early success of the Norwood procedure. ${ }^{1,2}$ The hybrid procedure - stenting of the arterial duct combined with banding of the pulmonary arteries (PAs) and atrial septectomy-appeared to reawaken some of the presumed errors of early pediatric cardiac surgery; for example, bilateral PA banding, and seemed contrary to the trend toward earlier aggressive reparative neonatal cardiac surgery. Contemporaneously, results with stage I surgical palliation continued to improve, with experienced centers soon reporting in-hospital survival rates of $85 \%$ to $90 \%$ in standard-risk patients. ${ }^{3}$ However, patients deemed to be at higher risk as a result of prematurity, very-low birth weight, chromosomal abnormalities, or pulmonary venous obstruction continued to experience mortality rates ranging from $25 \%$ to $40 \%$. The hybrid procedure, by virtue of its avoidance of cardiopulmonary bypass and myocardial

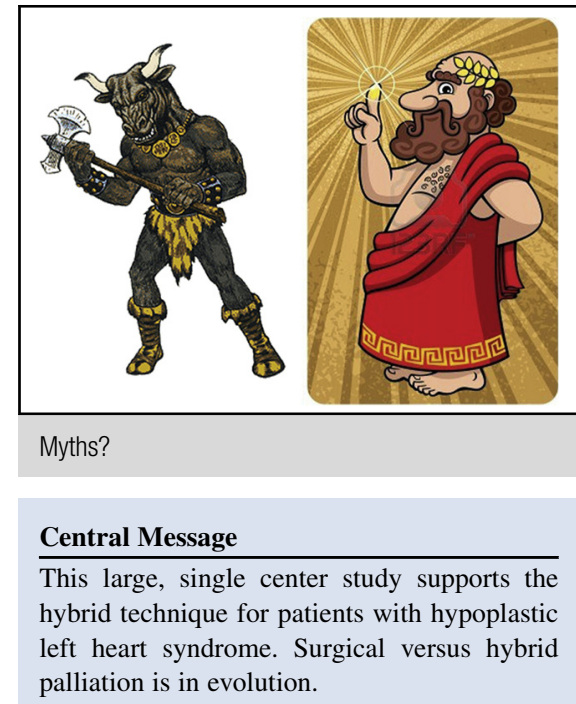

See Article page 1112.

See Editorial page 909.

ischemia, was offered to these high-risk patients with surprisingly good results. ${ }^{4}$ A few centers continued to refine the hybrid technique and offered it routinely to their patients with HLHS. ${ }^{5}$ 


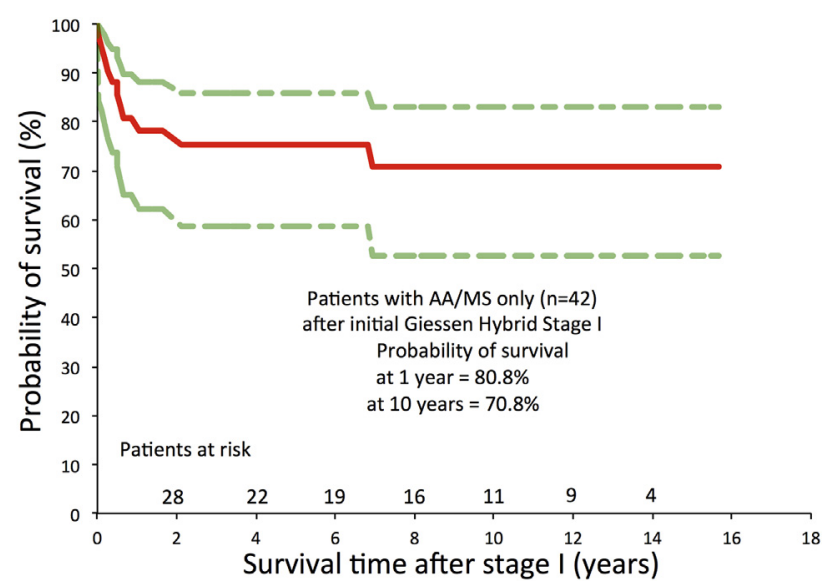

FIGURE E1. Probability of survival of patients with aortic atresia and mitral stenosis $(\mathrm{n}=42)$ after Giessen hybrid stage I (red curve) and $95 \%$ confidence limits ( green dotted curve). AA, Aortic atresia; $M S$, mitral stenosis. 
TABLE E1. Anesthesiology standards for Giessen hybrid stage I and comprehensive stage II procedures

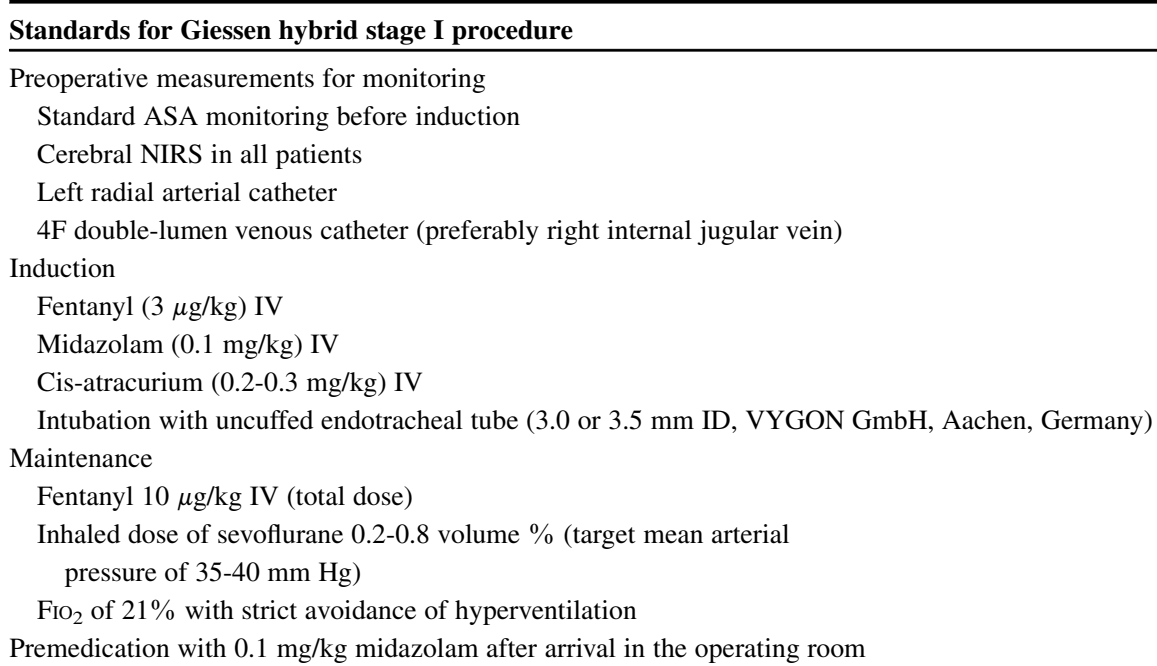

Standards for Giessen comprehensive stage II operation

Preoperative measurements for monitoring

Standard ASA monitoring

Standard 2-site simultaneous cerebral and somatic (renal) NIRS monitoring

Induction

Dexamethasone $(1 \mathrm{mg} / \mathrm{kg})$ IV before induction

Remifentanil $(0.5 \mu \mathrm{g} / \mathrm{kg} / \mathrm{min})$

Midazolam $(0.1 \mathrm{mg} / \mathrm{kg}) \mathrm{IV}$

Cis-atracurium $(0.2-0.3 \mathrm{mg} / \mathrm{kg}) \mathrm{IV}$

Endotracheal intubation and inhaled sevoflurane for maintenance

Measurements for intraoperative monitoring

2 arterial line catheters (preferably right radial and femoral arteries each)

2 central venous line catheters (4F double-lumen through the left subclavian and in general 5F double-lumen via 1 femoral vein)

$\mathrm{FIO}_{2}$ adjusted to keep $\mathrm{SpO}_{2}$ at $\sim 85 \%$ before cardiopulmonary bypass

Sevoflurane (0.2-0.8 vol \%) and remifentanil $(0.3-1.0 \mu \mathrm{g} / \mathrm{kg} / \mathrm{min})$ to maintain MAP $\geq 40 \mathrm{~mm} \mathrm{Hg}$

Continuous infusion of cis-atracurium $(0.1-0.2 \mathrm{mg} / \mathrm{kg} / \mathrm{h})$ throughout the procedure

Milrinone bolus $50 \mu \mathrm{g} / \mathrm{kg}$ over $10 \mathrm{~min}$ followed by $0.5 \mu \mathrm{g} / \mathrm{kg} / \mathrm{min}$ after the placement of central venous lines

Just before start of cardiopulmonary bypass 1 dose of clonidine $5 \mu \mathrm{g} / \mathrm{kg}$

On cardiopulmonary bypass

Second dose of dexamethasone $(0.5 \mathrm{mg} / \mathrm{kg})$

1 dose of phentolamine $(0.25 \mathrm{mg} / \mathrm{kg})$ just before the start of cooling to $28^{\circ} \mathrm{C}$

Intermitted hemofiltration (target hemoglobin $\geq 10 \mathrm{mg} / \mathrm{dL}$ )

Antegrade cerebral perfusion

Target mean arterial pressure in the right radial artery $\geq 40 \mathrm{~mm} \mathrm{Hg}$

Target cerebral NIRS level of $>65 \%$

Pump flow range $25-40 \mathrm{~mL} / \mathrm{kg} / \mathrm{min}$

Rewarming period

Continuous sodium-nitroprusside $(1 \mu \mathrm{g} / \mathrm{kg} / \mathrm{min})$ until cessation of bypass

Start of the mechanical ventilation with $\mathrm{FiO}_{2}$ of $100 \%$ and $20 \mathrm{ppm}$ inhaled nitric oxide after airway suctioning after the release of the Glenn circulation Hemofiltration and red blood cell transfusion (target hemoglobin level $14 \mathrm{mg} / \mathrm{dL}$ ) before weaning of cardiopulmonary bypass

Inotropes

Norepinephrine $(0.1-0-3 \mu \mathrm{g} / \mathrm{kg} / \mathrm{min})$ with target mean arterial pressure of $40 \mathrm{~mm} \mathrm{Hg}$

Supplemental clonidine to keep heart rate $<160$ beats/min

Blood coagulation

Tranexamic acid for antifibrinolysis throughout the procedure

Guidance of blood coagulation using activated clotting time measurement and thromboelastography (ROTEM, Tem International GmbH, Munich, Germany)

ASA, American Society of Anesthesiologists; NIRS, near-infrared spectroscopy; $I V$, intravenous; $I D$, inner diameter; $\mathrm{F}_{I} \mathrm{O}_{2}$, inspired oxygen fraction. 
TABLE E2. Cardiology standards for Giessen hybrid stage I, comprehensive stage II, and stage III (Fontan) procedures

Standards for Giessen hybrid stage I procedure

Parental Consent

The interventional-surgical hybrid procedure is performed after written parental consent following comprehensive instructions for the parents by prenatal and postnatal parental consultations. These instructions include not only the technical aspects of the hybrid stage I but also all steps of the provided procedures and their short- and long-term consequences for the patient and family. Probable comorbidities and syndromes, and alternatives such as Htx, but even the option to accompany the natural course of their newborn child are discussed in an extensive manner.

Surgical BPAB in elective patients

Mostly only low-dose continuous PGE1 infusion (2-10 ng/kg/min depending on duct size and flow pattern)

Morphologic and hemodynamic diagnosis by clinical assessment and TTE

In selected patients cMRI (if comorbidities or obvious syndromic signs)

Avoidance of intubation, ventilation, and oxygen supplementation

Avoidance of medication leading to increased myocardial oxygen consumption

Afterload reduction and medication to decrease myocardial oxygen consumption (if tachycardia, tachypnea, and high $\mathrm{PaO}_{2}$ and impaired systemic blood flow as in case of "pulmonary run off")

Surgical off-pump BPAB under general anesthesia with nasotracheal intubation within the first 5 postnatal days.

Intensive care management after surgical BPAB

Immediate extubation

Monitoring of $\mathrm{HR}$ and spontaneous breath pattern and rate, the upper and lower body $\mathrm{PaO}_{2}$

Intermittent right arm and leg blood pressure measurements

Ductal stenting

Ductal-stenting and manipulation of atrial septum electively in stable patients 1-10 d after BPAB

Percutaneous catheterization via femoral access only under sedation, local anesthesia, and spontaneous breathing

In case of contraindications for ductal stenting after BPAB, long-term PGE1 treatment. We usually perform BPAB first, which is followed by ductal stenting in the catheterization laboratory via transfemoral approach. The main reason for this alternative approach is to delineate the precise anatomy of the aortoductal junction, which varies considerably case by case in the catheterization laboratory instead of in the operating room. We can provide a wide variety of stents in Europe, in particular self-expandable stents CE marked for ductal stenting in newborns, which can be placed accustomed to the unique anatomy of the aortoductal region. Another advantage of this approach is to actively prevent inadvertent placement of the ductal stent too far into the descending aorta. This problem has been described by centers that combine bilateral banding and ductal stenting in the operating room. Third, but more important $(\sim 30 \%)$ in newborns with HLHS, there may be a requirement for a manipulation of the atrial septal communication that may be performed concomitantly but before duct stenting.

Type of stent

With the availability of newly designed, self-expandable Sinus-superflex-DS stents (OptiMed Inc, Karlsruhe, Germany) with CE mark for duct stenting, the delivery system can be advanced through a 4F sheath, even with a stent width of 7, 8 , and $9 \mathrm{~mm}$ and different lengths of 12, 15, 18, and 20 mm. The approach is routinely performed by femoral artery access. If interatrial manipulation becomes necessary, a femoral vein access is also established. The type of the stent is adjusted on ductal anatomy and morphology of the ductal-aortic junction. The chosen stent width is usually 1 to $2 \mathrm{~mm}$ above the measured duct width and always bigger than the descending aorta.

In case of a narrowed aortic isthmus or an aortic coarctation implantation of a short $(9 \mathrm{~mm})$ stent, a Sinus-repo self-expandable-DS stent with a width of 5 or $6 \mathrm{~mm}$ is used.

After ductal stenting, no routine anticoagulation is performed. If $\geq 2$ stents are implanted with the telescope technique, no cyclooxygenase inhibitor is used, but clopidogrel $(0.2 \mathrm{mg} / \mathrm{kg}$ once daily) is administered. Atrial septum manipulation including stenting is performed in patients with restrictive atrial septum and a mean pressure gradient $>5$ to $7 \mathrm{~mm} \mathrm{Hg}$.

Follow-up after Giessen hybrid stage I

Considering the clinical condition and desired echocardiographic (see later) and hemodynamic parameters 8-10 d after hybrid stage I completion, elective patients are discharged home following detailed advice for parents on how to monitor their infant (ie, checking the breath rate during sleep).

Within the first month: weekly visits with clinical and transthoracic echocardiography controls

Until stage II in those aged 4-5 mo, visits might be extended to every second week

Clinical assessment during interstage I visits

Parental history (breath rate in sleep, body weight development)

Breath and heart rate control

Pre- and postductal systolic and diastolic blood pressure measurement

Mean blood pressure measurements are not acceptable for control

Pre- and postductal $\mathrm{PaO}_{2}$, if antegrade perfusion (HLHS with MS, AS)

Routinely checked TTE parameters

- Systolic and diastolic right ventricular function together with tricuspid and pulmonary valve competence

- Morphologic and functional (mean and maximum pressure gradient) atrial communication 
TABLE E2. Continued

- BPAB gradients, in context of blood pressure, gradient across the stented duct, and the IAS gradient after exclusion of pulmonary vein obstruction

- Patency of the arterial duct, velocity through the noncompliant stented duct is mostly acceptable until Vmax $2.8 \mathrm{~m} / \mathrm{s}$, but always in context of RV function (TAPSE) and pulmonary valve competence

- Antegrade/retrograde aortic arch perfusion, which includes morphologic analysis of the aortic arch and ascending aorta arch connection (tube, golfwhole-like). Cerebral artery flow (right-sided anterior cerebral artery) in context of right arm blood pressure, but in consideration of an excluded innominate artery.

- Truncus arteriosus coeliacus flow characteristics in context of duct flow and systolic diastolic blood pressure measurements at the noncatheteraffected leg

\section{Standards for Giessen comprehensive stage II operation}

Timing for comprehensive stage II at an age of 3-6 mo

Planning of stage II based on clinical and echocardiography assessments

Imaging: TTE (see above)

cMRI routinely before stage II

No standard preoperative cardiac catheterization

Intensive care management after comprehensive stage II

Continuous monitoring: (HR, SAP, PAP, IVC, TPG, $\mathrm{SaO}_{2}-\mathrm{SvO}_{2}$, NIRS, core and peripheral temperature)

Ventilation: controlled, low-frequency, high tidal volume, prevention of atelectasis, permissive hypercapnea (positive base excess), or immediate SIMV ventilation with mean airway pressure $<8 \mathrm{cmH}_{2} \mathrm{O}$ (support passive flow of BDG)

Mild analgosedation but free of pain (low-dose fentanyl, ketamine) and with comfort (low-dose midazolam, and B-hydroxybutyric acid (5-20 mg/kg/d) in continuous infusion, sodium control!)

iNO 20-40 ppm if high SVC pressure (exclusion of LPA obstruction)

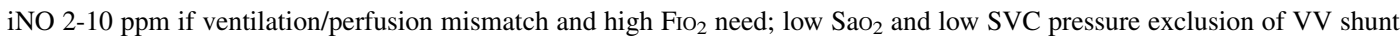

Sildenafil for weaning of iNO (prevent rebound)

Early extubation within the first $6 \mathrm{~h}$ postoperatively by using CPAP/high-flow ventilation

Balancing of $\mathrm{VO}_{2} / \mathrm{DO}_{2}$ with focus to reduce $\mathrm{O}_{2}$ demand.

Heart rate control by a central body temperature $<37^{\circ} \mathrm{C}$

Continuous clonidine infusion (maximal $3 \mu \mathrm{g} / \mathrm{kg} / \mathrm{h}$ ) (cumulation! if heart rate $<90$ beats $/ \mathrm{min}$ )

Early $\beta 1$-selective $\beta$-blockers (bisoprolol) $(0.05 \mathrm{mg} / \mathrm{kg} / \mathrm{d}$ once daily), in particular if inotropes required for RV support and coronary perfusion pressure due to a transient vascular leakage

Routine continuous milrinone (max $1 \mu \mathrm{g} / \mathrm{kg} / \mathrm{h})$

By indication: levosimendan and/or norepinephrine, both depending on myocardial function and/or blood pressure and coronary blood flow

Continuous furosemide $(6 \mathrm{mg} / \mathrm{kg} / \mathrm{d})$ together with theophylline $(5 \mathrm{mg} / \mathrm{kg} / \mathrm{d})$ infusion for the first few postoperative days to avoid/treat postoperative leakage; rapid weaning to establish oral drugs (see below)

Anticoagulation with heparin (300 IE/kg/d); start $6 \mathrm{~h}$ after surgery until central lines are removed

Postoperative cardiac medication before discharge

Bisoprolol $(0.05-0.15 \mathrm{mg} / \mathrm{kg} / \mathrm{d}$ once daily), heart rate dependent, goal $<120$ beats $/ \mathrm{min}$ at rest

Lisinopril (0.05-0.15 mg/kg/d once daily), blood pressure and urine output dependent.

Hydrochlorothiazide (1-2 $\mathrm{mg} / \mathrm{kg} / \mathrm{d}$ once or twice daily) for feeding ad libido.

Spironolactone ( $2 \mathrm{mg} / \mathrm{kg} / \mathrm{d}$ once daily) to attenuate RV fibrosis and pulmonary vascular resistance

Sildenafil, if transpulmonary pressure gradient $>7 \mathrm{~mm} \mathrm{Hg}$

Postoperative cardiac medication after discharge (all drugs, once daily)

Bisoprolol $(0.05-0.15 \mathrm{mg} / \mathrm{kg} / \mathrm{d}$ once daily), heart rate dependent, goal $<120$ beats $/ \mathrm{min}$ at rest

Lisinopril (0.05-0.15 mg/kg/d once daily), blood pressure and urine output dependent

Spironolactone ( $2 \mathrm{mg} / \mathrm{kg} / \mathrm{d}$ once daily) to influence RV fibrosis and pulmonary vascular resistance

Acetylsalicylic acid (2-3 mg/kg/d), anticoagulation only, if genetic disposition or stent in pulmonary artery

Sildenafil $3 \times 1 \mathrm{mg} / \mathrm{kg}$, by indication

Follow-up interstage II

See interstage I, but TEE 1/mo within the first 3 visits followed by 3 -mo intervals

cMRI before Fontan completion as routine imaging

Cardiac catheterization in any case, if there is not a contraindication

Standards for stage III operation (Fontan completion)

Preoperative evaluation

Goal: assessment of risk factors for Fontan circulation

Routine TTE (by indication TEE) 


\section{TABLE E2. Continued}

Focus on tricuspid valve in context of ventricular function including "ventricular synchrony" cMRI

- cardiac size and function

- ventricular inflow function, which includes the systemic and pulmonary vein flow

- assessment of pulmonary arteries and reconstructed aortic arch

- measurement of cardiac output, pulmonary blood flow, and distribution

- exclusion of ischemic areas (late enhancement)

Cardiac catheterization

- assessment of right (systemic) ventricular end-diastolic pressure, mean pulmonary artery pressure, and transpulmonary gradient (PAP-IVC[LA] pressure)

- flow parameters $\mathrm{SaO}_{2}-\mathrm{SvO}_{2}$, and pulmonary flow distribution (in particular in stented LPA)

- aortic arch reassessment including coronary arteries and ascending to neoaorta junction

- exclusion of significant venoatrial and aortopulmonary collateral vessels

Intensive care after Fontan completion (as routine, similar to after stage II)

Cardiac medication after discharge

- Bisoprolol (0.1-0.15 mg/kg/d once daily)

- Lisinopril (0.1-0.15 mg/kg/d once daily)

- Spironolactone $1-2 \mathrm{mg} / \mathrm{kg} / \mathrm{d}$ once daily

- Sildenafil ( $2 \mathrm{mg} / \mathrm{kg} / \mathrm{d}$, if TPG $>7 \mathrm{~mm} \mathrm{Hg})$

- Phenprocoumon in case of Fontan conduit fenestration (INR, 2.5-3)

- Acetylsalicylic acid 2-3 mg/kg/d in low-risk case and nonfenestrated Fontan conduit

Follow-up visits

Semiannual visits with TTE evaluation

cMRI every 1-3 y after Fontan completion

By indication: cardiac catheterization

ASA, American Society of Anesthesiologists; $\mathrm{NIRS}$, near-infrared spectroscopy; $\mathrm{IV}$, intravenous; $\mathrm{FiO}_{2}$, fraction of inhaled oxygen; $\mathrm{SpO}_{2}$, peripheral capillary oxygen saturation; $M A P$, mean arterial pressure; $B P A B$, bilateral pulmonary artery banding; $P G E 1$, prostaglandin E1; TTE, transthoracic echocardiography; $c M R I$, cardiac magnetic resonance imaging; $\mathrm{PaO}_{2}$, peripheral arterial oxygen saturation; $H R$, heart rate; $H L H S$, hypoplastic left heart syndrome; $M S$, mitral stenosis; $A S$, Aortic stenosis; $R V$, right ventricle; TAPSE, tricuspid annular plane systolic excursion; $S A P$, systemic arterial pressure; $P A P$, pulmonary artery pressure; $I V C$, inferior vena cava; $T P G$, transpulmonary gradient; $S a o_{2}$, arterial oxygen saturation; $\mathrm{SVO}_{2}$, (mixed) venous oxygen saturation; $S I M V$, synchronized intermittent mandatory ventilation; $B D G$, bidirectional Glenn; $i N O$, inhaled nitric oxide; $S V C$, superior vena cava; $L P A$, left pulmonary artery; $V V$, venovenous; $C P A P$, continuous positive airway pressure; $V O_{2}$, oxygen consumption; $D O_{2}$, global oxygen delivery; $T E E$, transesophageal echocardiography; $L A$, left atrium; INR, international normalized ratio; IAS, interatrial septum. 